\title{
Measurement of soil shear wave velocity using in situ and laboratory seismic methods - some methodological aspects
}

\author{
Tomasz GODLEWSKI ${ }^{1, *}$ and Tomasz SZCZEPAŃSKI ${ }^{2}$ \\ 1 Building Research Institute, Department of Geotechnics and Foundation, Ksawerów 21, 02-656 Warszawa, Poland \\ 2 University of Warsaw, Institute of Hydrogeology and Engineering Geology, Żwirki i Wigury 93, 02-089 Warszawa, Poland
}

Godlewski, T., Szczepański, T., 2015. Measurement of soil shear wave velocity using in situ and laboratory seismic methods - some methodological aspects. Geological Quarterly, 59 (2): 358-366, doi: 10.7306/gq.1182

\begin{abstract}
This article presents the results of seismic shear wave velocity $\left(V_{S}\right)$ measurements using the CSWS/SASW (continuous surface wave system/spectral analysis of surface waves) and SDMT (seismic flat dilatometer) methods, as well as BET (bender element test), on an experimental test site (and samples taken from it). The test site, a geologically relatively uniform alluvial sand formation area, was carefully chosen and checked for uniformity by means of drillings and soundings. The research aimed to determine how results from indirect, non-invasive surface geophysical tests (SASW and CSWS) correspond with those from SDMT penetration tests as well as the BET laboratory seismic method, and how some methodological aspects can influence them. Different wave sources and frequency were examined as the main factors for interpretation. The influence of other examined factors is also discussed.
\end{abstract}

Key words: seismic methods, shear wave velocity, methodology influence.

\section{INTRODUCTION}

Determination of soil-structure interaction demands that properly determined parameters be used with a particular design method. In the case of deformation modulus determination, it is essential to take into consideration these moduli-corresponding stress-strain range of the particular construction together with possible dynamic loads (Matthews et al., 2000; Młynarek et al., 2012). It means that these moduli should correspond to the so-called small strain, semi-elastic range of deformations.

Realization of non-linearity of stress-strain relationship has led to the need of measuring soil stiffness over a range of small deformations $\left(10^{-5} \div 10^{-3}\right)$ and utilization of many methods for this purpose (Fig. 1). The fact that these methods of stiffness parameter determination provide useful results is confirmed by back analysis calculations based on the data from monitoring of existing structures (Godlewski and Szczepański, 2011).

The results analysed in this article were obtained in the second phase of research on this topic. The first comparison and validation of methods were previously carried out on chosen test sites in Warszawa (Barański et al., 2010). In the first stage of the research, two kinds of surface seismic methods, using Rayleigh waves (CSWS and SASW) and seismic dilatometer

\footnotetext{
* Corresponding author, e-mail: t.godlewski@itb.pl
}

Received: November 19, 2013; accepted: May 5, 2014; first published online: July 22, 2014
SDMT, were used. Details on the equipment, methodology and measurement techniques can be found in Matthews et al. (2000), Menzies (2000), and Barański and Szczepański (2007) for surface geophysics, and in Marchetti et al. (2008) for SDMT. In the CSWS method, a vibrator was the wave source, while for SASW, it was a car wheel. In the SDMT test, a hammer and perpendicular beam were used as the vibration source. The device was constructed according to the design of SDMT manufacturers (Marchetti et al., 2008).

It should be borne in mind that different methods utilize different ways of propagation of seismic waves, i.e. direction of propagation and polarity (for methods used in this research: SDMT and BET - vertically propagating waves, horizontally polarized, SASW/CSWS - more complex wave movement because of using Rayleigh waves; Schneider et al., 1999).

As a background data for this paper, some previous results are presented in Figure 2. Five types of soils were tested by means of two methods (CSWS/SASW and SDMT). The selected profiles consisted of layers with various properties, lithology and origin, and were classified according to the SBT (Soil Behaviour Type) classification rule of Robertson (2009). These were Miocene-Pliocene clays of the Poznań Formation (over cosolidation - OC), Pleistocene varved clays (OC), Pleistocene tills of the Wartanian and Odranian glaciations (OC), Pleistocene (Eemian Interglacial) limnic soil - gyttja (OC), and young Holocene alluvial soil - soft silty clay (normal consolidation - NC).

The analysed profiles were from 10 to $20 \mathrm{~m}$ deep. The comparative analysis was based on the graphs of directly measured values, in this case measurements of shear $(S)$ wave velocity $V_{s}$.

It may be noticed that the values obtained from the SDMT method are generally slightly higher across the profile than 


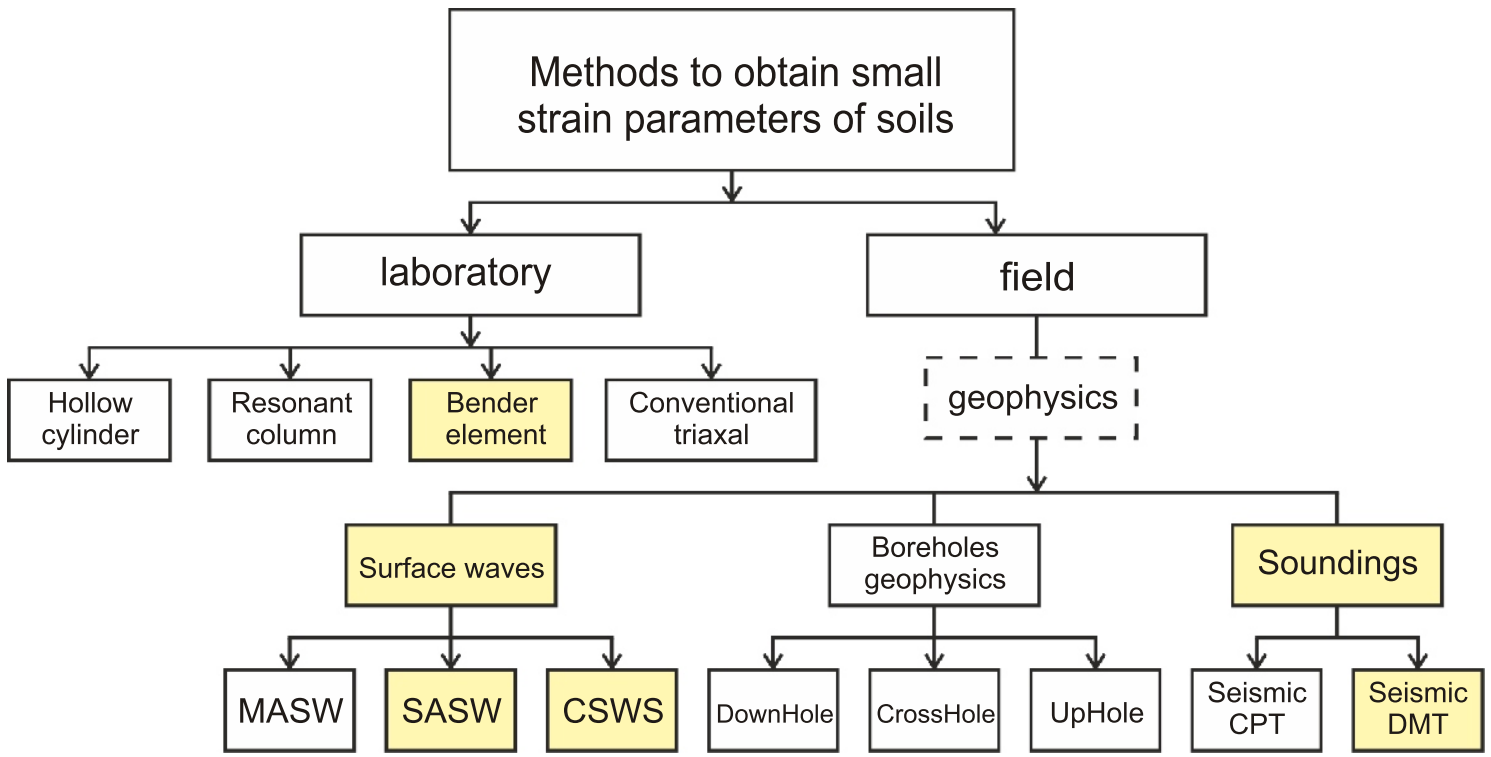

Fig. 1. Main methods of stiffness parameter determination (methods described in the article are marked yello; after Godlewski and Szczepański, 2012)

\section{$V_{s}[\mathrm{~m} / \mathrm{s}]$}

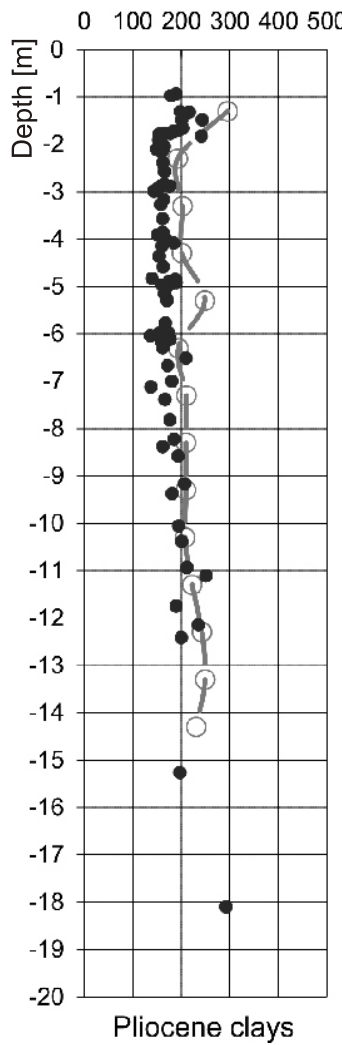

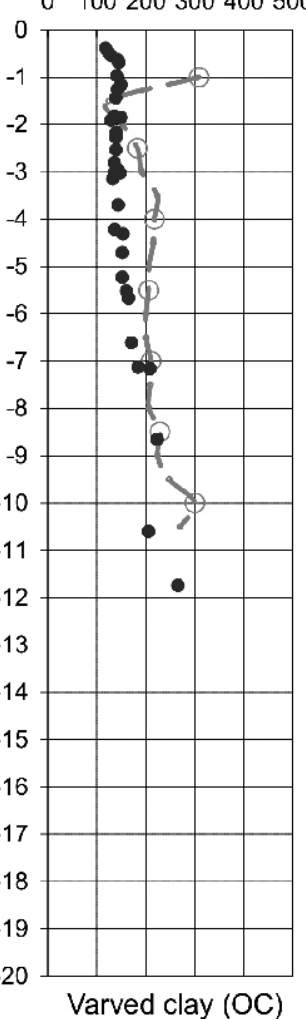

- CSWC/SASW 0 -SDMT

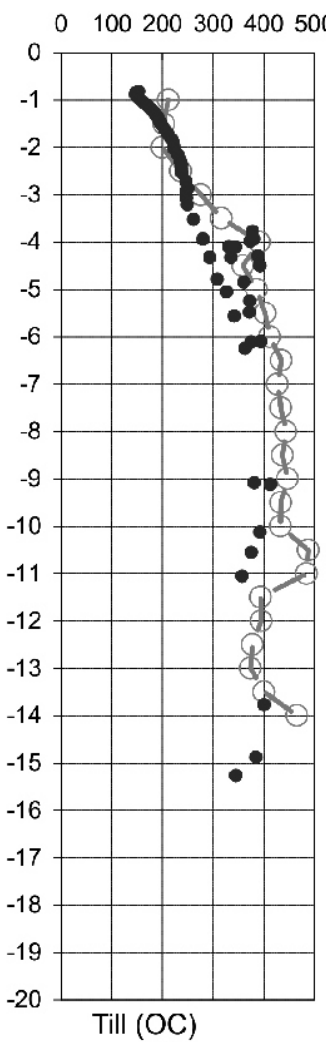

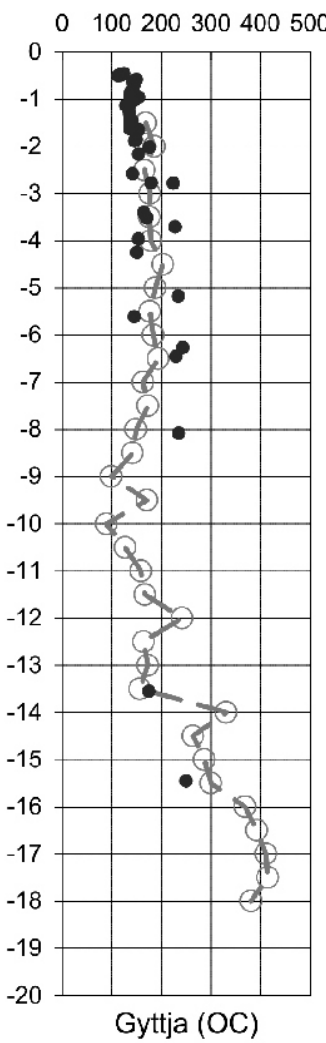

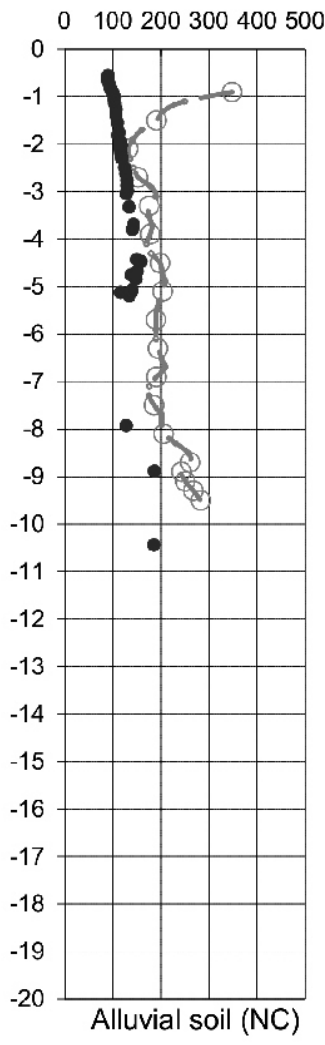

Fig. 2. Results of direct measurements of $S$-wave velocity $\left(V_{S}\right)$ versus depth for the analysed soil types 


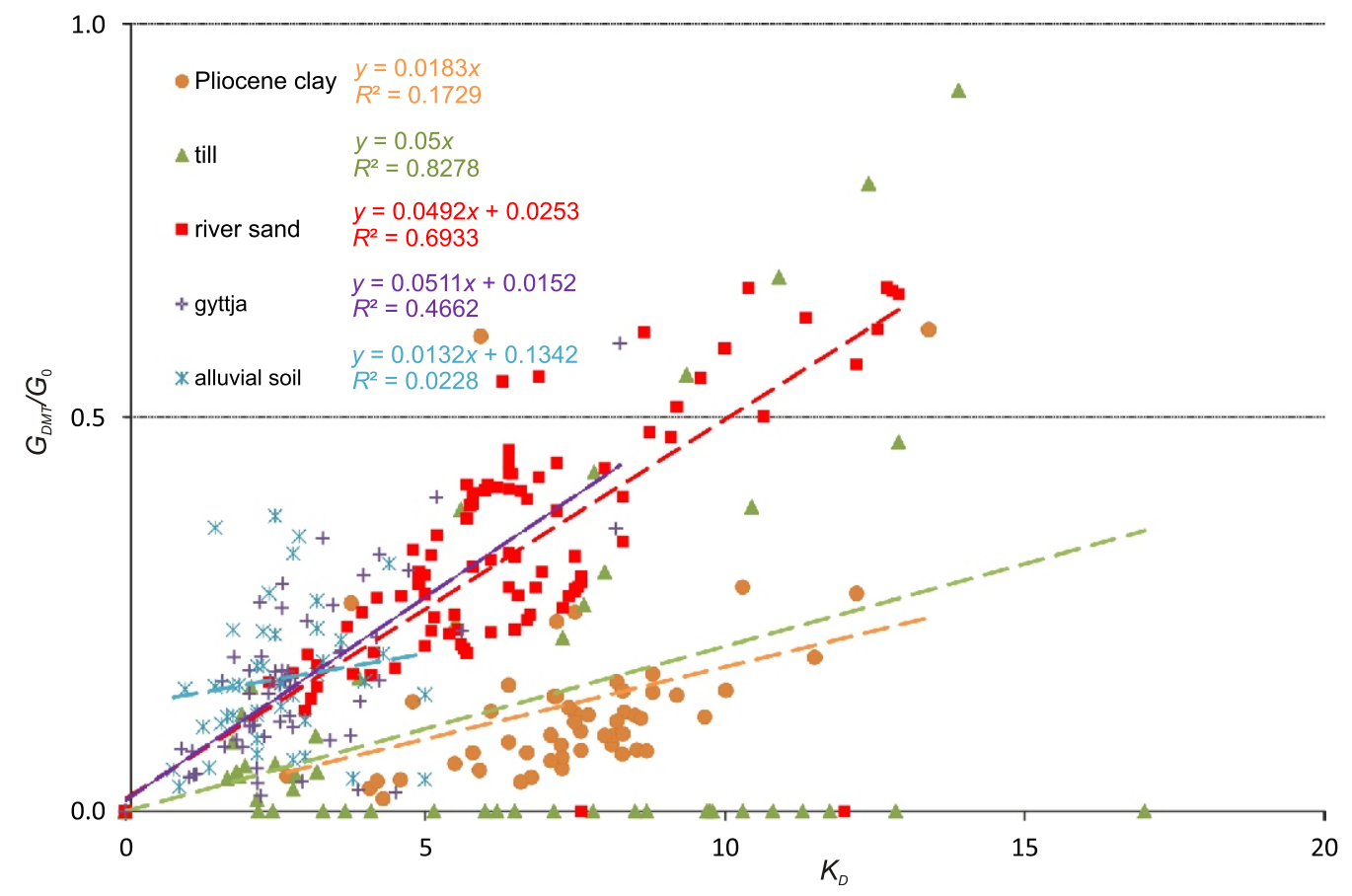

Fig. 3. The relationship $G_{D M T} / G_{0}$ vs. $K_{D}$ for various soil types from analysed test sites

those from CSWS/SASW, which is probably caused by a local change of stress due to the introduction of the dilatometer blade preceding the geophones, but this assumption needs to be verified, and other (also methodological) causes should be examined.

Another contribution to this paper was a trial to create correlations of $G_{D M T} / G_{0}$ as a function of $K_{D}$. Such relationship was presented originally by Monaco et al. (2009), and theoretically allows assessment of $G_{0}$ having only $G_{D M T}$ (calculated from dilatometer modulus $M_{D M T}$ ) and $K_{D}$ (horizontal stress index from dilatometer) from the standard DMT test. To create such correlations, many SDMT tests have been performed, during which standard DMT parameters have been gathered as well as shear wave velocity measurements. Figure 3 shows the graph of $G_{D M T} / G_{0}$ as a function of $K_{D}$ for each SBT; data gathered by the authors.

The data presented here is the first correlation of this type for soils in Poland. The amount of data is already statistically significant in some cases (e.g., sands); however, the coherence of the results is still below the level of significance for the relationship. The observed scatter undoubtedly originates partly from the variability and diversity of the studied material. Nevertheless, it should be checked how the results can be influenced by factors associated with the methodology. In case of seismic methods, consideration should be given to the type of sources used for producing waves and to the selection of the frequency. In the authors' opinion, methodological aspects may affect results variation similarly as properties of the subsoil itself (porosity, state of stress).

To summarize this introduction, the authors realized that, to have better understanding of the data gathered, additional parallel research has to be conducted, which can show how the non-standardized (in neither national standards nor international codes) test procedures can vary and what impact this can have on the results. An attempt was made to assess these as- pects through a series of experimental studies performed on the test site. For that purpose, field methods were used, both involving penetration (SDMT) and noninvasive (methods of surface geophysics), as well as examination with an advanced apparatus with piezoelectric sensors (BET). Some of the output of these tests are presented herein.

\section{DESCRIPTION OF THE EXPERIMENTAL TEST SITE}

The test site was located in a river valley on an over flood terrace on the east bank of the Wisła River near Warszawa (Fig. 4A). The test site, $30 \times 30 \mathrm{~m}$ in size, a geologically uniform area of Holocene (NC) alluvial sand formation, was carefully chosen and checked for uniformity by means of drillings and soundings (every $7.5-3.75 \mathrm{~m}$ ). This test site was discussed and analysed in detail in the doctoral dissertation concerning the evaluation of the changeability of alluvial soil (Sokołowska, 2011). The coefficient of horizontal variation does not exceed an average of $10 \%$ across the profile, when the finally chosen area of $7.5 \times 7.5 \mathrm{~m}$ is considered (Fig. 4B).

Within this site, the selected area was divided into a grid of $3.75 \mathrm{~m}$ squares, in which both seismic tests were performed. The test site arrangement is shown in Figure 5A. Apart from typical SDMT tests (locations A, B, C, D), non-standard experimental tests were also performed. These were carried out with the use of a different energy source (height from which a hammer was dropped), at location C. In case of SASW, two different energy sources were also used - a hammer and a car wheel. The details and results of these experiments are given in the next chapter. Following all in situ tests, a samples of soil (sand) were taken from the borehole at different depths for laboratory tests (BET). It was necessary to verify the impact of the frequency on the results obtained. 


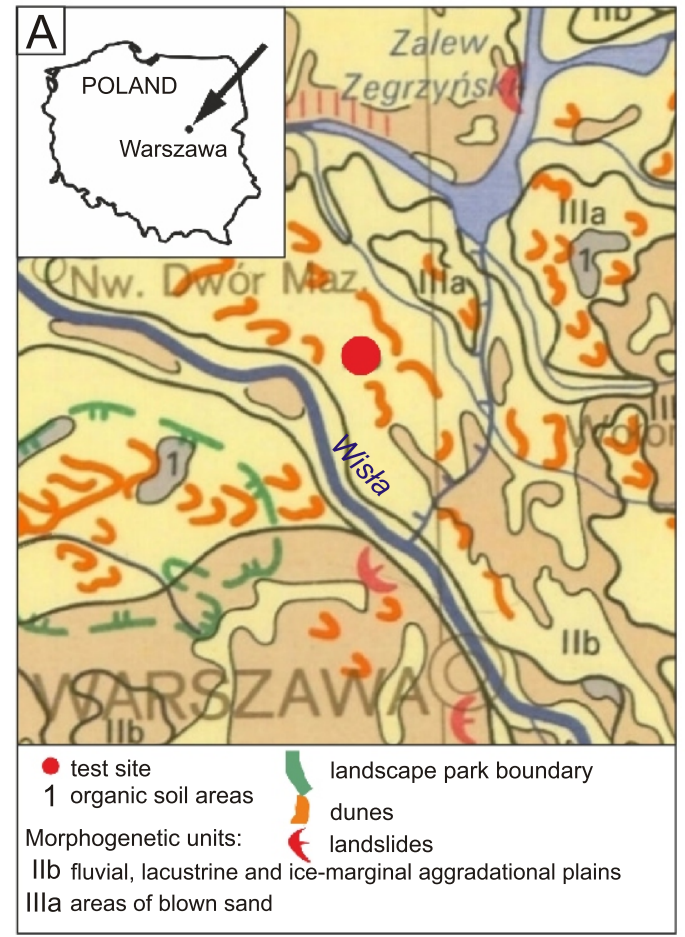

B

\section{Profile}

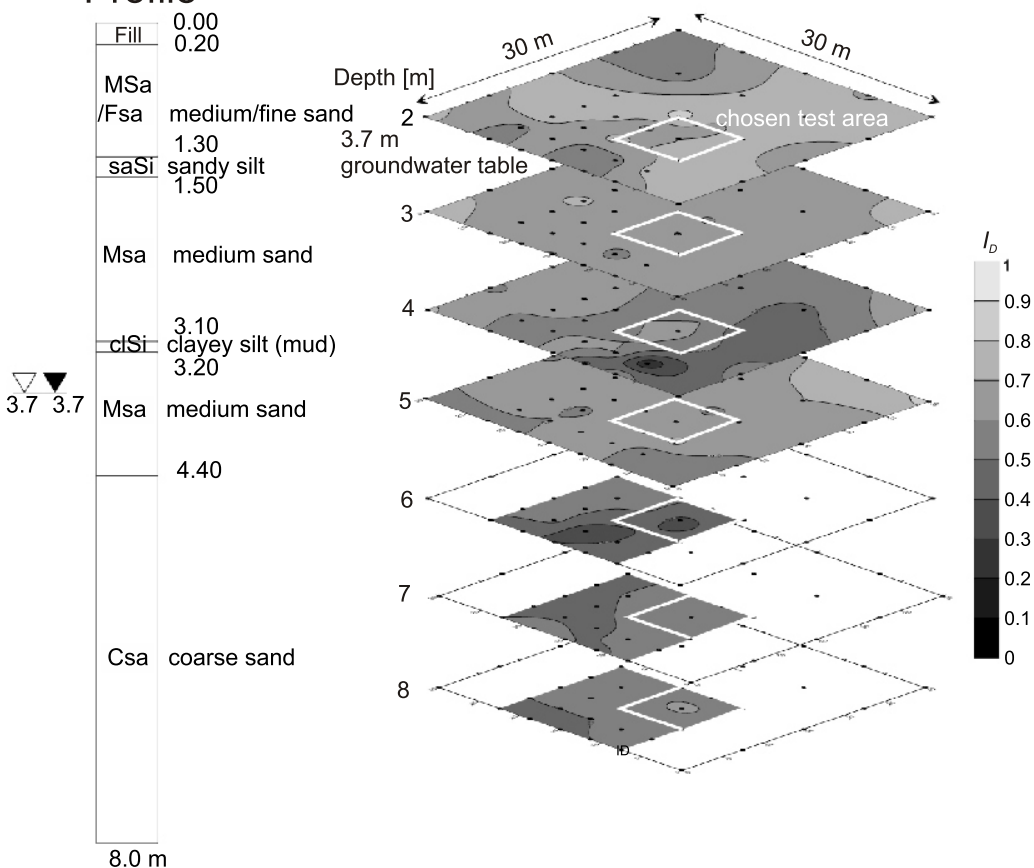

Fig. 4A - location sketch (on a fragment of engineering-geological map 1:500,000, Jakubicz and Łodzińska,1994); B - geotechnical characteristics of the general test site - profile and variability as a function of density index $I_{D}$ (Godlewski and Szczepański, 2012)
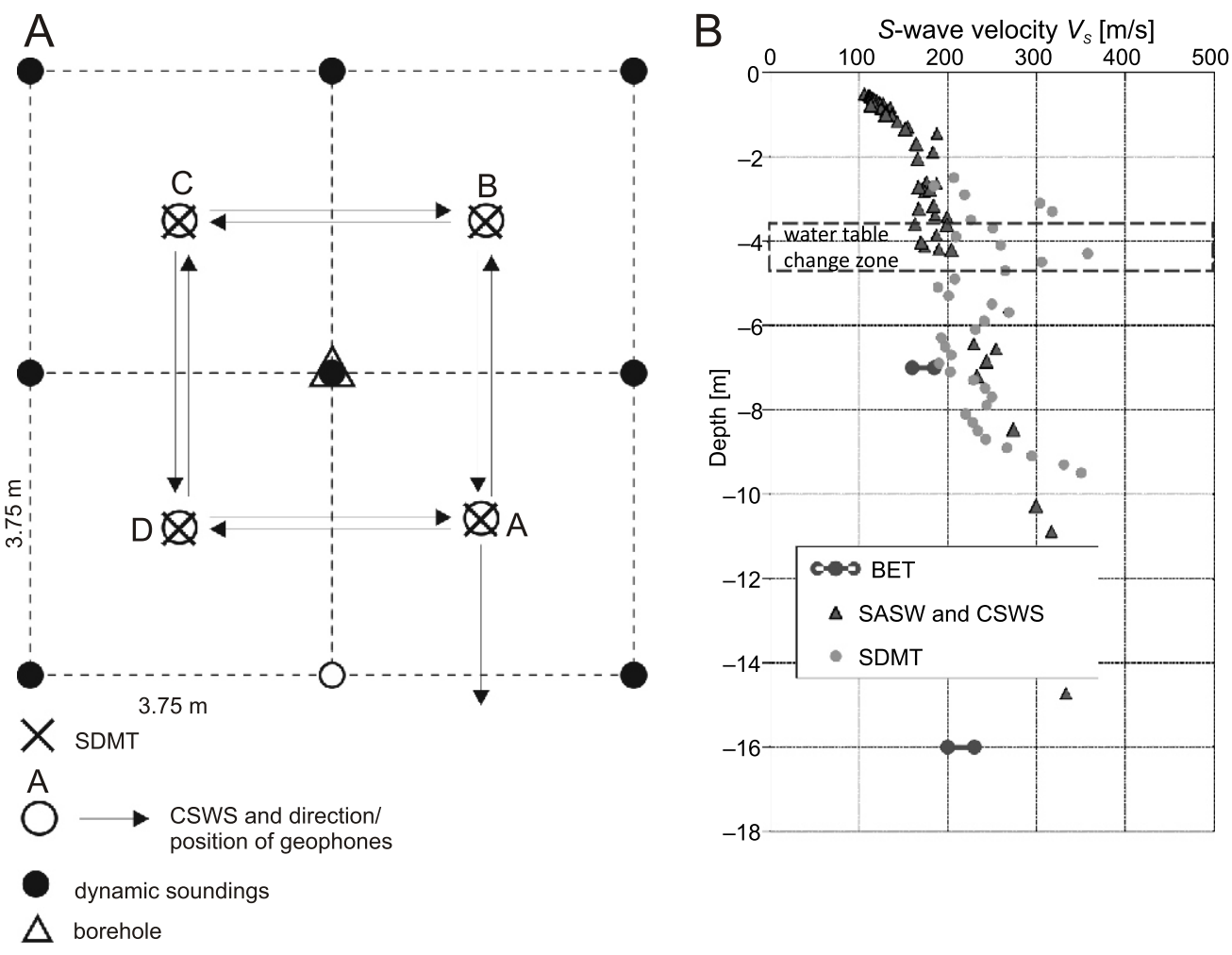

Fig. 5A - plan view of the test setup on the chosen test area; $B$ - example of shear wave velocity measurement from all methods used (location D) 


\section{RESULTS}

\section{INFLUENCE OF ENERGY SOURCE - SDMT}

The measured shear wave velocity speed depends mainly on the type of the soil, its density (void ratio $e$ ), the state of effective stress $p$, and the geological history. Different spectra of frequencies and amplitudes are generated during tests using different kinds of energy sources. Consequently, the quality and repeatability of the data as well as effective test depth can be affected.

In case of SDMT tests, the best results (Marchetti et al., 2008) in terms of the above-mentioned factors are achieved with use of a hammer connected with a handle to a perpendicular beam in such a way that, when dropped, it moves in pendulum-like movements, striking a steel beam at the lowest point. To explore how the amount of energy affects the quality of the signal in SDMT, two tests were performed at the site in different ways. At each test depth, three measurements were made with the drop of a hammer from a horizontal position $\left(90^{\circ}\right.$, "full energy"), and three measurements with the drop of a hammer from a $45^{\circ}$ position (for simplicity called "half energy"). The results of the experiment are shown in Figure 6.

It can be seen that the varying input energy can have an influence on the results. Differences in S-wave velocity at particular test depths can be as high as $80 \mathrm{~m} / \mathrm{s}$. These discrepancies are mainly due to various interpretations of recorded seismograms. At shallow depths, the signals registered from geophones when the "half energy" method was used were clean, whereas at "full energy" in many cases they exceeded the geophone amplitude range or contained a great deal of interference and noise (Fig. 6). Even when filtered with available software tools, such a signal is often difficult to interpret. On the other hand, when the depth of the test exceeds $8 \mathrm{~m}$, the "half energy" method gives signals that are far too weak and not sufficiently distinct from the background noise, and are thus subject to a considerable error. In that case, only the "full energy" method gives sufficient signal quality for unambiguous interpretation. In the middle part of the profile tested (4-8 m), both methods give similar-looking seismographs and shear wave velocity results. The coefficient of variation for the results obtained in the central zone is lower. At the top and bottom of the profile, the impact of the energy source causes dispersion of the results.

A quite obvious but important conclusion that can be drawn from the above is that, in planning tests based on the "down hole" principle (as with the SMDT test), it is good to start with lower energy input in the vibration source, and to increase it with depth. In that way, the signals acquired will be of higher quality and easier to interpret.

\section{INFLUENCE OF ENERGY SOURCE - SASW}

Surface seismic methods are based on interpretation of Rayleigh wave propagation. The waves travel at depths related to wavelength, so the depth of the test depends on the frequency generated. Using the CSWS sub-method, the frequency-controlled vibrator makes it possible to control the signal content. On the other hand, with the SASW sub-method, the choice of a vibration source can have a great influence on the results.

The authors have been experimenting for a few years generally with two kinds of energy sources - a traditional sledge hammer and a car wheel. As there is a clear dependency between wavelength (and thus frequency) and test penetration depth, the latter solution proves its advantage in many cases. Giving a "softer" impact, the generated frequency spectrum contains much lower range frequencies, covering effectively test depths of up to $15 \mathrm{~m}$ or even greater. An example comparison of results obtained with the use of the two described sources is shown in Figure 7A, where less data scatter and greater penetration have been achieved with use of an impact source alternative to the traditional hammer (test at location A).
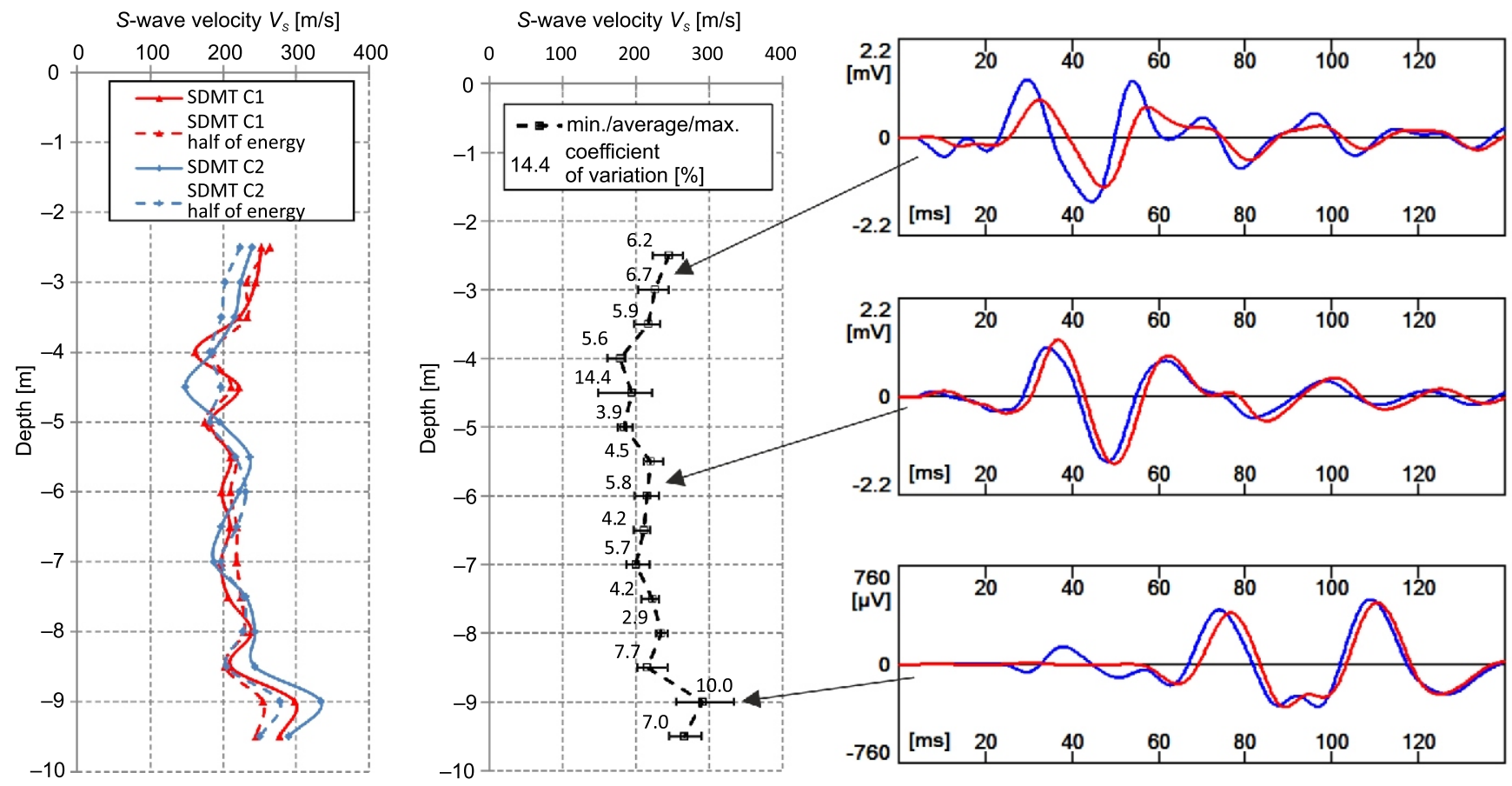

Fig. 6. Results of SDMT tests with input energy differentiated, examples of seismograph at the different depth and variability for whole profile ( $V_{s}$ value) 

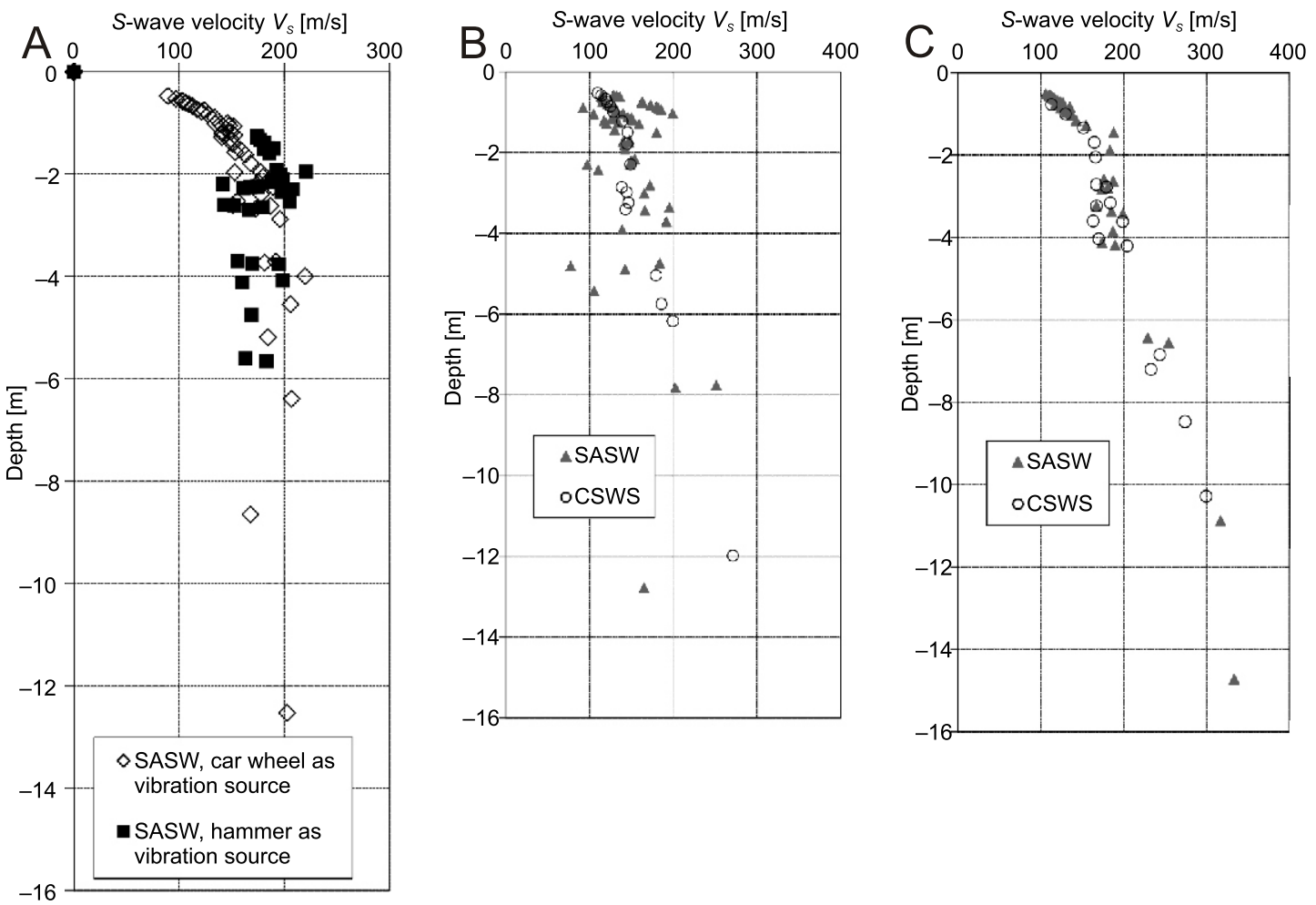

Fig. 7A - comparison of SASW test results, two different vibration sources used;

B - impact of ambient noise on the dispersion of the SASW results; C - complementary use of a surface seismic method to increase the accuracy and depth of testing - examples from experimental site

Comparing the results from SASW and CSWS we can see reasonably good agreement (Fig. $7 \mathrm{C}$; location D, Fig. 5A). On the other hand, when the test is conducted in a noisy environment (heavy equipment working nearby during the test; Fig. 7B; location C, Fig. 5A), CSWS data stay consistent with each other (because of fully controlled frequency content of the source signal), while SASW data are much more scattered.

Nevertheless, practice shows that the best way to utilise the full potential of the surface seismic sub-methods (CSWS, SASW) is to use both complementarily, if available (Fig. 7C). The advantage of controlled frequency cannot be overestimated when using the CSWS system (it enables minimisation of the impact of interference), whereas the main benefits of the spectral analysis method are faster testing and the ability to use sources of different kinds matching current requirements and capabilities.

\section{THE FREQUENCY ASPECT - BET}

Although bender elements are widely used worldwide to assess shear wave velocity, there is still no unique methodology for the performance and interpretation of this test (although some suggestions are published and widely known in the literature, for example the results of an international parallel test conducted by the Japanese Technical Committee TC-29 (Yamashita et al., 2009).There are several crucial aspects, and two of them are examined here.

The first is the problem of subjectivity of interpretation of wave travel time. Generally, three methods of interpretation are commonly applied: cross correlation of the signals, spectrum analysis, and an observational method relying on visual interpretation. The last one is most commonly used in practice, but it is also the most subjective. For this reason, in some ap- proaches this process is automated to some extent by creating software tools to handle it. One such tool, made available for free public use by GDS Instruments (Rees et al., 2013), has been utilised in this work, and the data gathered using it are analysed further. The tool allows, among other things, interpretation in the time domain (TD), with use of the four most common points of interest on the output signal (in comparison to time zero): A - first deflection, B - first bump maximum, C zero after first bump, and D - major first peak (Lee and Santamarina, 2005; see Fig. 8).

The reason for using different criteria is that the received signal is usually far from being perfect, and only one or two points of interest can be identified at once. In the data presented below, methods $B, C$, and $D$ are used, the output of method $A$ being rejected on account of the unacceptable scatter of the data.

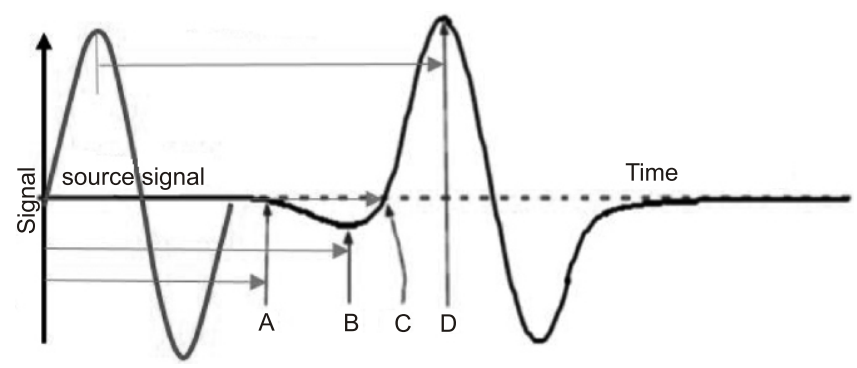

Fig. 8. Idealized received signal output of a S-wave (after Lee and Santamarina, 2005)

A - first deflection, B - first bump maximum, $C$ - zero after first bump, D - major first peak 
The second aspect examined here regarding the BE Test is the choice of source wave frequency range. Preferably, the user would like to have a specified recommended frequency, which could reduce subjectivity in comparing test results. Unfortunately, there are some factors that make this approach impossible - tests on different soils under different conditions show that the use of any particular single frequency does not permit the achievement of good wave propagation, and thus good results. Additionally, it is sometimes suggested (Camacho, 2012) that the ratio of the wavelength to the height of the sample should not be smaller than 2, due to near field effects. At the same time, recommendations made by TC-29 state that a range of frequencies should be used (for example $1-14 \mathrm{kHz}$ ) in order to assess the quality of the results and then to make a selection.

Having the above in mind, tests on an isotropically consolidated, fully saturated specimen of coarse sand from the depth
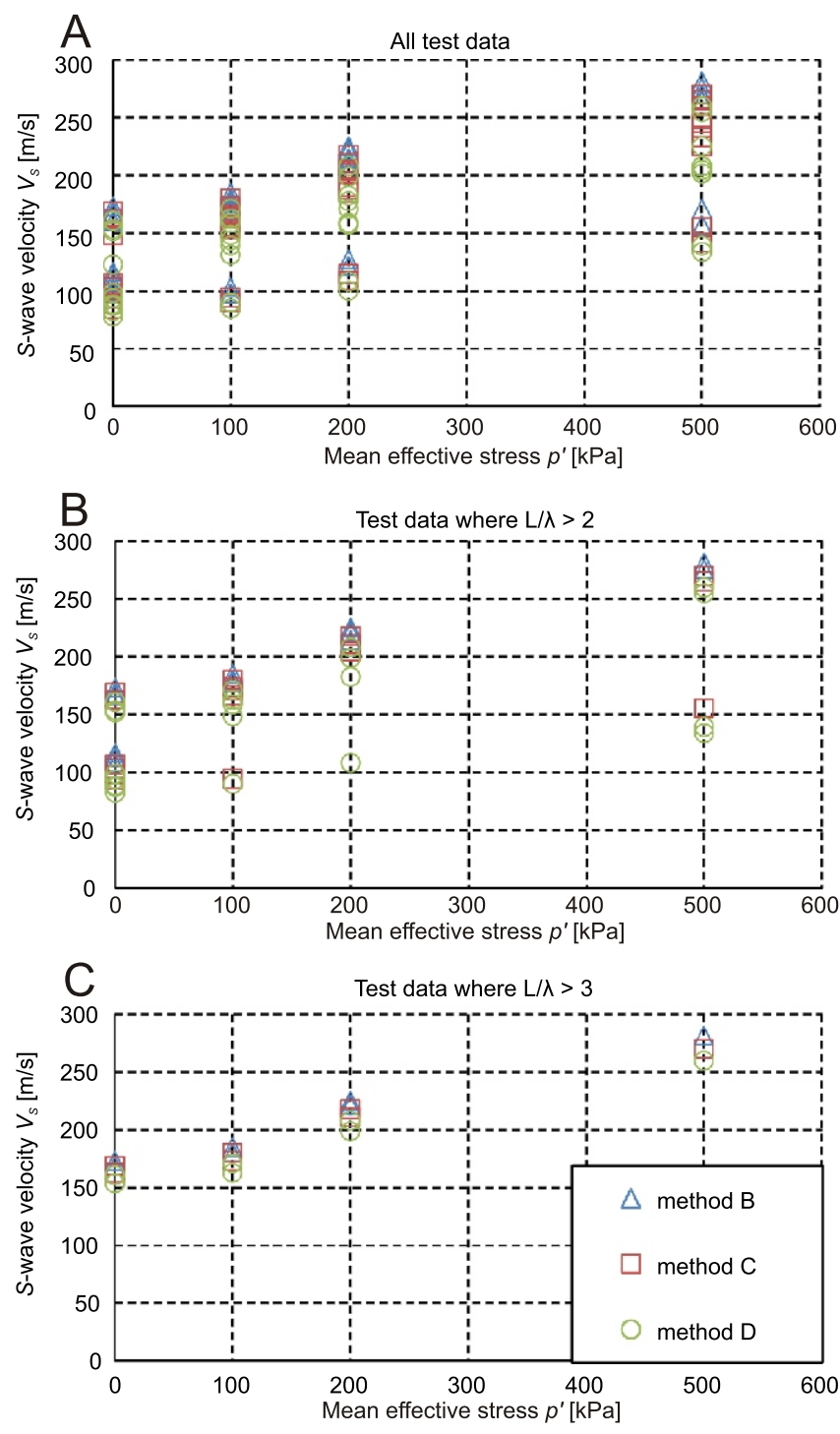

Fig. 9. BE Test data on sand from the test site, tests with $p^{\prime}=0,100,200,500 \mathrm{kPa}$

A - data from all source wave frequencies;

B - data filtered to satisfy the condition $L / \lambda=2$;

C - data filtered to satisfy the condition $L / \lambda=3$ of $8 \mathrm{~m}$ from the experimental test area were performed under the following conditions: sample diameter $70 \mathrm{~mm}$, sample height $135 \mathrm{~mm}$, source frequency range $1-10 \mathrm{kHz}$ (every 1 $\mathrm{kHz}$ ), mean effective stress $p^{\prime}=0,100,200,500 \mathrm{kPa}$, travel-time interpretation by methods $\mathrm{B}, \mathrm{C}$ and $\mathrm{D}$ (automated using BEAT software). Sample was prepared to have density index $I_{D}=0.5$ at the beginning of the test. Back pressure during saturation and during the test has been kept equal $500 \mathrm{kPa}$.

Figure 9A shows the combined results of all tests performed, interpreted according to all of the aforementioned travel-time interpretation methods. The data grouped in vertical lines for each mean effective stress represent results from different frequencies and interpretation methods; thus the whole graph depicts the range of the values of shear wave velocities that could be obtained by different researchers using various $f$ (frequency) and travel-time estimates. When analysing $f$ versus $V_{S}$, for example for mean effective stress $p^{\prime}=100$ (Fig. 10A), it

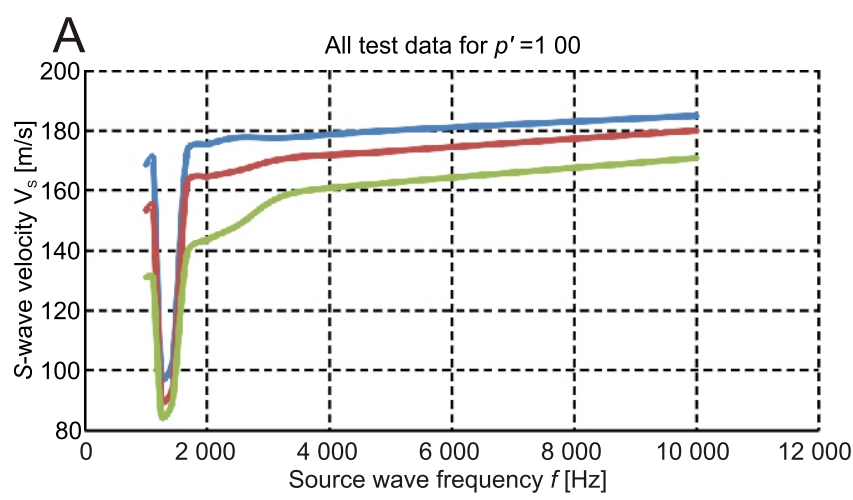

B
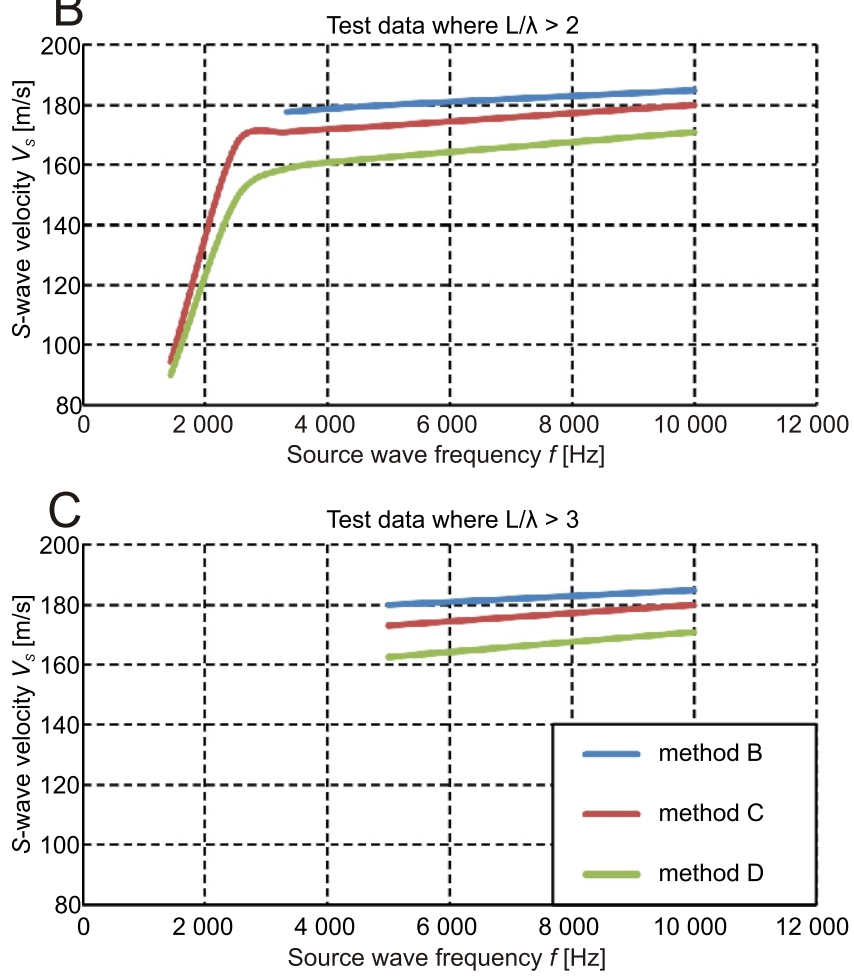

Fig. 10. BE Test data on sand from the test site, test with $p^{\prime}=100 \mathrm{kPa}$

A - data from all source wave frequencies;

B - data filtered to satisfy the condition $L / \lambda=2$;

C - data filtered to satisfy the condition $L / \lambda=3$ 
can be noticed that the $V_{S}$ values are most consistent with each other (especially between methods $B$ and $C$ of travel-time interpretation) in the higher range of frequencies.

The first way to assess which frequencies should be considered reliable is to check the ratio between the travel distance and the wavelength $(L \lambda)$. If the wavelength is too close to the height of the sample (travel distance), a huge impact from the near field effect (Lee and Santamarina, 2005) is usually observed, which masks the proper signal. Recommendations found in the literature say that this value should be within the range $2<L \lambda<9$ (Camacho, 2012). Appropriate calculations were made, and data filtered out to match those conditions. The value of $L \lambda=2$ as a lower limit did not work satisfactorily, as can be seen for the example data set corresponding to $p^{\prime}=100$ (Table 1) and for all results (Fig. 10B). Further filtering was performed with $L \lambda=3$ as a lower limit. The results for all of the data filtered accordingly are shown in Figure 10C.

The importance of being aware of such limitations in $\mathrm{BE}$ testing is not to be underestimated. Usual laboratory practice is to rely on the use of a single frequency, and in the authors' experience it is not reliable to judge just by the visual appearance of a received signal whether or not the near-field effect is masking the actual signal and impairing the final estimate of $V_{s}$. It is recommended to perform analysis using a range of frequencies, or at least as a minimum requirement to use a frequency which gives a value for the ratio $L \wedge$ of at least 3 .

To visualise the relationship between shear wave velocity $\left(V_{S}\right)$ and frequency $(f)$, depending on wave travel length $(L)$ (sample height for vertical measurement) and with the above-mentioned ratio equal to 3 , the graph shown in Figure 11 was plotted. This can be used as a quick guide to estimate the required minimum source wave frequency. For example, for material with expected $V_{S}$ around $200 \mathrm{~m} / \mathrm{s}$ and sample height $100 \mathrm{~mm}$ available (wave travel distance $L$ ), it can be assessed from the diagram in Figure 11 that we should use frequency about $6 \mathrm{kHz}$ or higher, to be sure that near-field effect does not affect the results. The diagram was calculated using equations: wavelength $\lambda=$ wave speed $V /$ wave frequency $f$, and 3 example sample sizes.

As regards shear wave travel-time interpretation methods, it can be observed from the data presented that methods $B$ and $\mathrm{C}$, which are the most commonly used, give the closest results, with method $D$ still within about $10 \%$ band of result scatter. Methods $\mathrm{B}$ and $\mathrm{C}$ also primarily reflect the theoretical approach of analysing the "first arrival" of the received signal, so these are predominantly recommended to be chosen whenever the time domain methods are considered. The software tool (BEAT)

Ta ble 1

Shear wave velocity estimates for $p^{\prime}=100 \mathrm{kPa}$, summarised

\begin{tabular}{|c|c|c|c|}
\hline & \multicolumn{3}{|c|}{ Shear wave velocities $V_{S}[\mathrm{~m} / \mathrm{s}]$} \\
\hline & \multicolumn{3}{|c|}{$\begin{array}{l}\text { Method of travel-time interpretation } \\
\text { (TD) }\end{array}$} \\
\hline & B & $\mathrm{C}$ & $\mathrm{D}$ \\
\hline \multirow{3}{*}{$\begin{array}{l}\text { All data for } p^{\prime}=100 \\
\text { (max./min./scatter) }\end{array}$} & 185 & 180 & 171 \\
\hline & 98 & 90 & 85 \\
\hline & 87 & 90 & 86 \\
\hline \multirow{3}{*}{$\begin{array}{l}\text { Data for } p^{\prime}=100 \text { and } \\
\mathrm{L} / \lambda>2 \text { (max./min./scatter) }\end{array}$} & 185 & 180 & 171 \\
\hline & 178 & 94 & 90 \\
\hline & 7 & 86 & 81 \\
\hline \multirow{3}{*}{$\begin{array}{l}\text { Data for } p^{\prime}=100 \text { and } \\
\text { L/ } / \lambda>3 \text { (max./min./scatter) }\end{array}$} & 185 & 180 & 171 \\
\hline & 180 & 173 & 163 \\
\hline & 5 & 7 & 8 \\
\hline
\end{tabular}

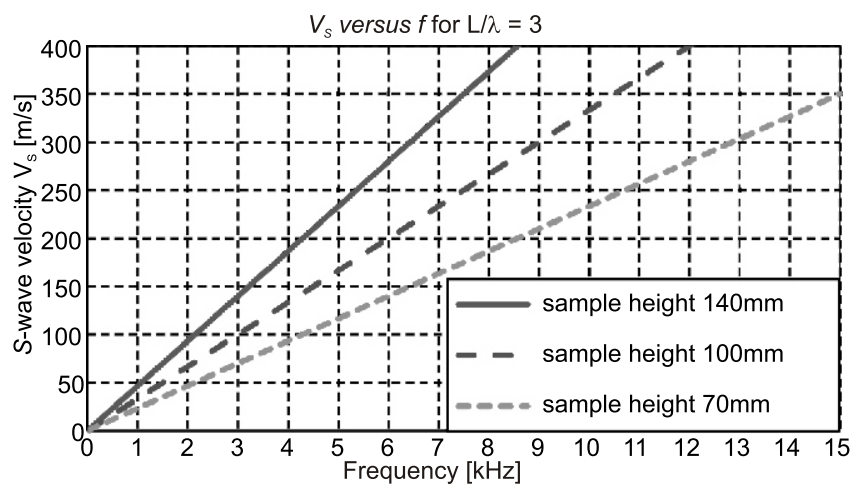

Fig. 11. Diagram proposed for assessment of proper choice of testing frequency for shear wave velocity measurement, depending on sample height and assuming $L / \lambda=3$ as the lowest permissible value

used to automate the process of analysis, and thus to decrease the degree of subjectivity, has proved its usefulness; however it must be kept in mind that the final word and decision must always belong to the operator.

\section{CONCLUSIONS}

Despite the different nature of the measurements by two field methods supported by laboratory tests (invasive for SDMT, non-invasive for CSWS/SASW, laboratory BET), results of $V_{S}$ measurements can be considered comparable, although BET results are below the in situ values in this case (Fig. 5B). This might be reflecting imperfect recreation of stress state and density of the material. Another observation from this graph is sensitivity of SDMT for local changes in $V_{S}$, stemming probably from the effects of water table fluctuation zone. Obviously, direct measurement in this method gives better resolution than inevitably averaged observations from indirect methods based on Rayleigh wave propagation.

Nevertheless, for correct practical application, some methodological aspects of those tests were preliminary examined.

SDMT and SASW test results can be influenced by the amount of energy and manner of application when the vibration spectrum is generated. An important factor when using the seismic dilatometer is to ensure that the signal amplitude is not exaggerated and is of proper quality, so varying the impact energy with depth is an advised solution. Surface spectral analysis is highly influenced by the frequency spectrum of the generated signal. CSWS has a fully controlled vibration source in terms of frequency, but its limitation lies in the relatively small vibrating mass (63kg inertial mass in the equipment used), which is often unable to generate waves "strong" enough at low frequencies (6-10 Hz) to achieve deep propagation.

As regards the most commonly used laboratory test for shear wave velocity assessment, the Bender Element Test, aspects of source wave frequency and travel-time interpretation have been analysed. It was found that the literature recommendations to choose a frequency for which the ratio of wave travel length to wavelength equals 2 may be underestimated in some cases. A ratio equal to 3 was found to be more appropriate for the data set analysed (river coarse sands CSa in this case). A diagram for estimation of the proper test frequency depending on shear wave velocity has been proposed in accordance with the sample dimensions used and assuming $L \lambda=3$. 
The selection of a method of travel-time interpretation seems not to be so crucial, as long as proper filtering of the data has been performed according to the above rules.

Acknowledgements. The presented results are one of the stages of research project referring to deformability of soils in laboratory and field tests with the use of seismic methods
(NG-51). This project is carried out by ITB in cooperation with the Institute of Hydrogeology and Engineering Geology at Warsaw University. The authors wish to express their thanks to Dr $M$. Barański and to the all anonymous reviewers for constructive criticism and comments on the manuscript. Special thanks also to Dr. Z. Frankowski and Prof. T.M. Peryt for editorial comments and handling of the manuscript.

\section{REFERENCES}

Barański, M., Szczepański, T., 2007. Zastosowanie metod sejsmiki powierzchniowej do oceny modułu G gruntu (in Polish). Czasopismo Techniczne. Pub. PK, z. 1-Ś/2007.3: 17-25.

Barański, M., Godlewski, T., Szczepański, T., 2010. Determination of soil stiffness parameters on chosen test sites, using in situ seismic methods. Proc. 4th Int. Workshop: Soil parameters from in situ and laboratory tests, Poznań, 149-157.

Camacho-Tauta, J.F., Alvarez, J.D.J., Reyes-Ortiz, O.J., 2012. A procedure to calibrate and perform the bender element test. Dyna, 79: 10-18.

Jakubicz, B., Łodzińska, W., 1994. Mapa Geologiczno-Inżynierska w skali 1:500 000 (in Polish). Państwowy Instytut Geologiczny. Wydawnictwo Kartograficzne Polskiej Agencji Ekologicznej S.A., Warszawa.

Godlewski, T., Szczepański, T., 2011. Nieliniowa charakterystyka sztywności gruntu $\left(G_{0}\right)$ - metody oznaczania i przykłady zastosowań (in Polish). Górnictwo i Geoinżynieria, 35 243-250.

Godlewski, T., Szczepański, T., 2012. Determination of soil stiffness parameters using in-situ seismic methods insight in repeatability and methodological aspects. Proc. of ISC'4, 17-21 September 2012, Porto de Galinhas-Pernambuco, Brazil, 1: 441-446.

Lee, J.S., Santamarina, J.C., 2005. Bender elements: performance and signal interpretation. Journal of Geotechnical and Geoenvironmental Engineering, 131: 1063-1070.

Marchetti, S., Monaco, P., Totani, G., Marchetti, D., 2008. In situ tests by seismic dilatometer (SDMT). Research to Practice in Geotechnical Engineering, Geotechnical Special Publication, ASCE, 180: 292-311.

Matthews, M.C., Clayton, C.R.I., Own, Y., 2000. The use of geophysical techniques to determine geotechnical stiffness param- eters. Proceedings of the Institution of Civil Engineers, Geotechnical Engineering, 143: 31-42.

Menzies, B., 2000. Near-surface site characterization by ground stiffness profiling using surface wave geophysics. In: H.C. Verma Commemorative Volume. Indian Geotechnical Society, New Delhi.

Młynarek, Z., Wierzbicki, J., Stefaniak, K., 2012. Deformation characteristics of overconsolidated subsoil from CPTU and SDMT tests. Proceedings of ISC'4, 17-21 September 2012, Porto de Galinhas-Pernambuco, Brazil, 2: 1189-1193.

Monaco, P., Marchetti, S., Totani, G., 2009. Interrelationship between Small Strain Modulus $G_{0}$ and Operative Modulus. IS-Tokyo Intnl Conference on Performance-Based Design in Earthquake Geotechnical Engineering, 1315-1324.

Rees, S., Compte, Le, A., Snelling, K., 2013. A new tool for the automated travel time analyses of bender element tests. Proc. of the 18th Int. Conference on Soil Mechanics and Geotechnical Engineering, Paris 2013, 2843-2846.

Robertson, P.K., 2009. Interpretation of cone penetration tests unified approach. Canadian Geotechnical Journal 46 , 1337-1355.

Schneider, J.A., Hoyos, L., Jr., Mayne, P.W., Macari, E.J., Rix, G.J., 1999. Field and laboratory measurements of dynamic shear modulus of Piedmont residual soils. Behavioral Characteristics of Residual Soils, GSP 92, ASCE, Reston, VA, 12-25.

Sokołowska, M., 2011. Ocena zmienności właściwości geotechnicznych gruntów aluwialnych jako podłoża budowlanego (in Polish). Ph.D. thesis, Instytut Techniki Budowlanej, Warszawa.

Yamashita, S., Kawaguchi, T., Nakata, Y., Mikami, T., Fujiwara, T., Shibuya, S., 2009. Interpretation of international parallel test on the measurement of $G_{\max }$ using bender elements. Soils and Foundations, 49: 631-650. 